\title{
The Impact of Maternal Relationship Quality on Emerging Adults' Prosocial Tendencies: Indirect Effects via Regulation of Prosocial Values
}

Carolyn McNamara Barry
Loyola College in Maryland

Laura M. Padilla-Walker

Brigham Young University - Provo

Stephanie D. Madsen

McDaniel College

Larry J. Nelson

Brigham Young University - Provo, larry_nelson@byu.edu

Follow this and additional works at: https://scholarsarchive.byu.edu/facpub

Part of the Other Social and Behavioral Sciences Commons

\section{Original Publication Citation}

Barry, C. M., Padilla-Walker, L. M., Madsen, S. D., \& Nelson, L. J. (2008). The impact of maternal relationship quality on emerging adults' prosocial tendencies: Indirect effects via regulation of prosocial values. Journal of Youth and Adolescence, 37, 581-591.

\section{BYU ScholarsArchive Citation}

Barry, Carolyn McNamara; Padilla-Walker, Laura M.; Madsen, Stephanie D.; and Nelson, Larry J., "The Impact of Maternal Relationship Quality on Emerging Adults' Prosocial Tendencies: Indirect Effects via Regulation of Prosocial Values" (2007). Faculty Publications. 4677.

https://scholarsarchive.byu.edu/facpub/4677

This Peer-Reviewed Article is brought to you for free and open access by BYU ScholarsArchive. It has been accepted for inclusion in Faculty Publications by an authorized administrator of BYU ScholarsArchive. For more information, please contact ellen_amatangelo@byu.edu. 


\title{
The Impact of Maternal Relationship Quality on Emerging Adults' Prosocial Tendencies: Indirect Effects via Regulation of Prosocial Values
}

\author{
Carolyn McNamara Barry · Laura M. Padilla-Walker • \\ Stephanie D. Madsen · Larry J. Nelson
}

Received: 28 August 2007/ Accepted: 4 October 2007 / Published online: 30 October 2007

(C) Springer Science+Business Media, LLC 2007

\begin{abstract}
Studies document that parents serve as children's primary socialization agents, particularly for moral development and prosocial behavior; however, less is known regarding parental influences on prosocial outcomes during the transition to adulthood. The purpose of this study was to investigate how mother-child relationship quality was related to prosocial tendencies via emerging adults' regulation of prosocial values. Participants included 228 undergraduate students (ranging from 18 to 25 years; 90\% European American) and their mothers (ranging from 38 to 59 years) from four locations across the United States. Path analyses using structural equation modeling revealed that mother-child relationship quality was related to emerging adults' regulation of prosocial values, which was, in turn, related to emerging adults' prosocial tendencies. Specifically, emerging adults who reported higher levels of internal regulation of prosocial values were more likely to report prosocial tendencies that de-emphasized themselves, and were less likely to report prosocial tendencies for the approval of others.
\end{abstract}

Portions of this study were submitted for presentation at the Society for Research in Adolescence biennial meeting in March 2008.

C. M. Barry ( $\square)$

Department of Psychology, Loyola College in Maryland, 4501 N. Charles St., Baltimore, MD 21210, USA

e-mail: cbarry@loyola.edu

L. M. Padilla-Walker · L. J. Nelson

Brigham Young University, Provo, UT, USA

S. D. Madsen

McDaniel College, Westminster, MD, USA
Keywords Prosocial behavior - Regulation of prosocial values · Parent-child relationship quality ·

Emerging adulthood

\section{Introduction}

Parents serve as children's primary socialization agents, particularly for moral development and prosocial behavior (Eisenberg and Murphy 1995). This lifelong parent-child relationship often serves as a context for socialization (Lawford et al. 2005). Scholars have investigated how parents' behaviors (e.g., modeling, disciplinary strategies, authoritative parenting) are associated with prosocial behaviors during childhood and adolescence (Holmbeck et al. 1995; Mussen and Eisenberg 2001). However, there is little research examining potential parental influences on prosocial behaviors for individuals between the ages of 18 and the mid-twenties. Such individuals, known hereafter as emerging adults, are in the process of transitioning to adulthood (i.e., conceptualizing oneself as an adult and acting accordingly), wherein they are redefining the parent-child relationship and are more likely to engage in risktaking behaviors (Arnett 2000). Moreover, there is scant literature (c.f., Barry and Wentzel 2006 for middle adolescents) examining the psychological processes to explain the relation between a socialization agent's behavior and an individual's prosocial behavior.

Emerging adults' focus on independence and identity exploration (Arnett 2000) may result in parenting that does not relate directly to child outcomes. Instead, parenting may relate indirectly through its influence on emerging adults' personal characteristics, such as beliefs (e.g., religious faith) and values (e.g., benevolence, social responsibility). Support for this possibility can be discerned 
from research suggesting that during late adolescence parenting begins to matter less in a direct way because the adolescent's personal characteristics become stronger predictors of child outcomes (Brown et al. 1993; Steinberg and Silk 2002). For example, one study found that parental expectations influenced adolescents' own positive values, which in turn impacted prosocial behaviors, but parenting was not related directly to adolescents' behaviors (PadillaWalker and Carlo in press). The role of personal characteristics on such outcomes may be even more pronounced during emerging adulthood when many parents and children no longer reside together. Nevertheless, the quality of the parent-child relationship has been shown to relate to child outcomes throughout that child's life (Blieszner and Wingfield 2000). Thus, parenting is believed to still matter to emerging adults, but may be best explained through indirect relations of parent-child relationship quality to child outcomes rather than direct ones. The current study examined the extent to which relationship quality, as perceived by both emerging adults and their mothers, was related to prosocial tendencies by way of emerging adults' regulation of prosocial values (i.e., regulation from an external source of control verses an internal one).

\section{Parent-Child Relationship}

Although there is a substantial literature on the role of the parent-child relationship on child and adolescent outcomes (see Bornstein 2006; Steinberg and Silk 2002), there is a paucity of literature on the nature of the parent-child relationship during emerging adulthood and its relation to child outcomes. According to Bowlby's (1969) attachment theory, parents do not abruptly stop parenting when children reach the age of 18 , and the continuity of the parentchild relationship continues to be important, especially during times of transition (Bartle-Haring et al. 2002; O'Connor et al. 1996). This idea is also consistent with Darling and Steinberg's (1993) theoretical framework suggesting that a high quality parent-child relationship has been associated with positive child outcomes, and there is some evidence that this continues to be important during emerging adulthood. For example, retrospective studies have documented that emerging adults who received parental acceptance, approval, and support as a child were likely to report high levels of self-esteem (Buri 1987) and form successful relationships with others (Dalton et al. 2006). Moreover, when maternal knowledge and maternal closeness were both high, emerging adults self-reported lower levels of alcohol and drug use (Padilla-Walker et al. 2007). Collectively, these results support the importance of the parent-child relationship as a buffer against risk behaviors and as a promoter of positive outcomes during emerging adulthood. Thus, although there is evidence of the importance of parenting during adolescence (Steinberg and Silk 2002) and middle-adulthood (Logan and Spitze 1996), the task undertaken in the current study was to substantiate the importance of parenting during the transition to adulthood.

\section{Regulation of Prosocial Values}

Parents socialize their children with a variety of beliefs, values, and behaviors. Within the realm of moral development, scholars have investigated the extent to which children internalize their parents' values and, therefore, shift their regulation of values from an external source of control (such as their parents) to an internal source of control (see Grolnick et al. 1997). This internalization process has been conceptualized as a continuum ranging from external regulation (i.e., external forces determine motivation such as punishment avoidance) to internal or integrated regulation (i.e., motivation is internal and autonomous; Grolnick et al. 1997), which is how regulation of values was conceptualized in the current study. Research has shown that aspects of parenting are instrumental in their children's regulation of values. Specifically, parents who reason with their children, use power assertion (i.e., rule setting and enforcing), and whose parenting is done with warmth, tend to promote children's internal regulation of values (Grusec and Goodnow 1994).

The relation between parenting and children's regulation of values has been explored predominantly in childhood because parental supervision is stronger in childhood than at subsequent points in the lifespan (e.g., Kochanska 1995). However, individuation and identity exploration begin in adolescence and continues throughout emerging adulthood, thus leading to experiences that may challenge parental values and, as a result, promote the internal regulation of personal values. Investigating regulation of prosocial values as a function of identity status (i.e., the level of identity commitment and exploration), Padilla-Walker et al. (in press) found that emerging adults with achieved identity statuses (indicating exploration and commitment) reported the highest scores on internal regulation of values, whereas those with a diffused status (indicating a lack of exploration and commitment) reported the lowest scores. Given that the transition to adulthood includes a continuation of the individuation process that is begun during adolescence (Jensen et al. 2004), it remains important to investigate the regulation of prosocial values, particularly because prosocial values act as a motivation for prosocial behavior (Bardi and Schwartz 2003; Padilla-Walker and Carlo in press). 


\section{Prosocial Behavior}

Although much media and research on emerging adulthood focuses on risk behaviors (Schulenberg and Zarrett 2006), scholars (e.g., Arnett 2004) have argued and recent research suggests that emerging adulthood is also a time during which individuals explore positive behaviors (PadillaWalker et al. in press), which range from volunteer service like the Peace Corps, to the display of prosocial behaviors (i.e., voluntary behaviors meant to benefit others; Carlo and Randall 2001). Given documented developmental improvements in social cognition along with the increased variety of social contexts in which emerging adults engage, there are increasingly more opportunities to display prosocial behavior during emerging adulthood than during childhood (e.g., Fabes et al. 1999). Emerging adults not only use this time period to engage in prosocial behaviors, but they also use this time in their lives to develop prosocial qualities in preparation for the future. For example, emerging adults rate "developing greater consideration for others" as a necessary criterion for adulthood (e.g., Arnett 2003; Mayseless and Scharf 2003), and it appears that the attainment of these other-oriented attributes are indeed indicative of having made the self-perceived transition to adulthood (Nelson and Barry 2005). Furthermore, Carroll et al. (2007) found that relational maturity (a construct reflecting prosocial attributes necessary for the formation and maintenance of relationships) is a key component for preparation for the adult roles of marriage and family life. Taken together, prosocial behavior is an important component of the transition to adulthood.

\section{Factors that Promote Prosocial Behavior}

Parents and peers clearly are important in the socialization of prosocial behaviors (e.g., Knafo and Plomin 2006; Laible et al. 2004). Scholars have documented the psychological processes that explain this behavior, namely modeling (e.g., Elliot and Vasta 1970), social-cognitive skills such as sympathy, empathy (e.g., Eisenberg and Fabes 1998), and perspective-taking (e.g., Eisenberg et al. 2001), as well as moral reasoning (e.g., Eisenberg 1986) and the adoption of values and motivations that favor prosocial behaviors (e.g., Wentzel et al. 2004). Eisenberg et al. (2002) contend that the degree to which one behaves prosocially is part of one's personality. Few scholars, however, have examined the psychological processes that explain how others socialize an individual to engage in prosocial behavior. For instance, Barry and Wentzel (2006) documented that a single best friend's prosocial behavior was related to an adolescent's prosocial behavior over one year by way of the adolescent's pursuit of prosocial goals. Thus, an individual's motivation to behave prosocially is part of the psychological process of friends' influence on prosocial behavior. Scholars have yet to examine parents' socialization of their emerging-adult children's prosocial behaviors, and whether this relation might be mediated by the child's own values.

\section{Types of Prosocial Tendencies}

Traditionally, scholars have investigated prosocial behavior as a global entity; however, situation-specific types of prosocial behaviors have been investigated more recently, and are referred to as prosocial tendencies. Specifically, Carlo and Randall (2002) have delineated six prosocial tendencies or motivations toward prosocial behaviors that are context-specific: public (i.e., helping others in front of an audience, motivated largely by approval), compliant (i.e., helping others when asked), emotional (i.e., helping others who are in emotionally evocative situations), dire, (i.e., helping in a crisis), anonymous (i.e., helping others without their knowledge), and altruistic (i.e., helping others with little regard for self consequences). In a review by Eisenberg and Fabes (1998), individual variability in the display of these prosocial tendencies has been noted. Specifically, Carlo and Randall (2002) found that individuals with high levels of altruistic tendencies reported high levels of moral reasoning and low levels of aggression in contrast to those who reported prosocial tendencies in more public settings and who reported high levels of approval-oriented prosocial moral reasoning. Padilla-Walker et al. (in press) found that, compared to individuals with identity achievement, moratorium, or foreclosure status, individuals with an identity-diffused status reported more frequent displays of public prosocial tendencies, and conversely reported less frequent displays of compliant, emotional, dire, and altruistic, prosocial tendencies. Additionally, they found that emerging adults with an identity-achieved status reported altruistic prosocial tendencies more than did emerging adults with the other three identity statuses. Thus, the type and degree of prosocial tendencies in which emerging adults engage depends upon their identity status, suggesting that the type of prosocial tendencies likely also depends on the degree to which emerging adults have internalized positive values (which is related to identity status). In the current study, we explored these context-specific types of prosocial tendencies (as delineated by Carlo and Randall 2002) to reveal a more complete understanding of this form of emerging adults' positive behavior.

\section{The Current Study}

As noted previously, prosocial behavior has been studied extensively among children (Eisenberg and Fabes 1998). 
This literature has demonstrated the role of socialization agents such as parents (e.g., Grusec and Goodnow 1994), particularly in terms of the quality of parent-child interaction (Blieszner and Wingfield 2000) in addition to psychological processes such as social-cognitive skills (e.g., Eisenberg et al. 2001) and motivation (e.g., Barry and Wentzel 2006) that promote prosocial behavior. However, comparatively less is known about how emerging adults come to engage in prosocial behavior as they individuate from primary socialization agents, i.e., parents. Although a father's role in children's prosocial outcomes is certainly important, existing research suggests that mothers are children's primary socialization agents, especially when focusing on positive values and behaviors (Grusec 2006); therefore, we focused exclusively on the mother-child relationship in the current study.

We hypothesized that having a high quality motherchild relationship (as perceived by both the emerging adult and the mother) would be related positively to emerging adults' internal regulation of prosocial values, which in turn would be related to high levels of prosocial tendencies, especially when there was little opportunity for recognition (e.g., altruistic prosocial tendencies). In contrast, we hypothesized that a high quality mother-child relationship would be related negatively to emerging adults' external regulation of values, which in turn would be related to lower levels of prosocial tendencies, particularly when doing so provided little opportunity for recognition. Given past research suggesting that adolescents' own personal values are a stronger predictor of their prosocial behaviors than are maternal values or expectations (Padilla-Walker and Carlo in press), we did not expect to see direct relations between relationship quality and prosocial tendencies. Rather, we expected relationship quality to relate to prosocial tendencies indirectly via emerging adults' regulation (external versus internal) of prosocial values.

\section{Method}

\section{Participants}

Participants for this study were drawn from an ongoing study of emerging adults and their parents entitled "Project READY" (Researching Emerging Adults' Developmental Years). This project is an ongoing, collaborative, multi-site study that is being conducted by a consortium of developmental and family scholars.

The sample selected for the current study $\left(M_{\text {age }}=19.95\right.$, $S D=1.92$, range $=18-25)$ consisted of 228 undergraduate students (132 women, 96 men) and their mothers $\left(M_{\text {age }}=\right.$ $48.79, \quad S D=4.41, \quad$ range $=38-59$ ). Participants were recruited from four college sites across the United States
(56\% from two mid-Atlantic colleges, 27\% from a Midwestern university, and $17 \%$ from a West Coast university). The majority of emerging adults were European American (90\% European American, 3\% African American, 3\% Asian American, $1 \%$ Latino American, and 3\% other). Ninety percent of emerging adults reported living outside of their parents' home in an apartment, house, or dormitory. Sixtyseven percent of mothers reported having a bachelor's degree or more, with $59 \%$ reporting an income of over $\$ 100,000$.

\section{Procedure}

Participants completed the Project READY questionnaire via the Internet (see http://www.projectready.net). The use of an online data collection protocol facilitated unified data collection across multiple university sites and allowed for the survey to be administered to emerging adults and their parents who were living in separate locations throughout the United States. Participants were recruited through faculties' announcement of the study in undergraduate and graduate courses. Undergraduate courses were primarily introductory psychology courses or large general education courses in an attempt to access a broad range of students. Professors at the various universities were provided with a student handout that had a brief explanation of the study and directions for accessing the online survey. Interested students then accessed the study website with a locationspecific recruitment code. Informed consent was obtained online, and only after consent was given could the participants begin the questionnaires. Each participant was asked to complete a survey battery of 448 items. Sections of the survey addressed topic areas such as background information, family-of-origin experiences, self-perceptions, personality traits, values, risk behaviors, dating behaviors, prosocial tendencies, and religiosity. Most participants were offered course credit or extra credit for their own and their parents' participation. In some cases, participants were offered small monetary compensation (i.e., \$10-20 gift certificates) for their participation.

After participants completed the personal information, they had the option to send an invitation to their parents to participate in the study via email. The email invitation included an assigned password and a link to the parents' version of the questionnaire. The parents were directed to click on the link and enter the password. Once the password was entered, an Informed Consent Form appeared and parents then followed the same protocol as the children. If parents did not have email addresses, mailing addresses were obtained and questionnaires were mailed to them with self-addressed, pre-paid envelops for them to mail back completed surveys (this happened with only 
one parent, and data did not differ from those gathered from online questionnaires). Parents completed a shorter battery of 280 items similar to the ones their children completed, asking them to respond from a parental point of view.

\section{Measures}

We examined emerging adults' and their mothers' reports of relationship quality, as well as emerging adults' reports of regulation of prosocial values (i.e., external and internal regulation of prosocial values) and prosocial behavior.

\section{Relationship Quality}

Mother-child relationship quality was assessed using four subscales of the Social Provisions Questionnaire (Carbery and Buhrmester 1998). Both emerging adults and their mothers rated three items for each of the four subscales (companionship, intimate disclosure, instrumental aid, and emotional support) on a scale that ranged from 1 (little or none) to 5 (the most). Sample items for each subscale include "How often do you turn to this person for support with personal problems?" for support $(\alpha=.86)$; "How much free time do you spend together?" for companionship $(\alpha=.81)$; "How much do you tell this person everything?" for intimate disclosure $(\alpha=.86)$; and "How much does this person help you figure out or fix things?" for aid $(\alpha=.77)$. Factor analysis on the scale items has yielded a distinct factor structure (Carbery 1993).

\section{Regulation of Prosocial Values}

Emerging adults' self-reported regulation of prosocial values was assessed using the Prosocial Self-Regulation Questionnaire (Ryan and Connell 1989), which assesses both external and internal regulation of values. Past research has used this measure on adolescent and emerging-adult populations and has found external and internal regulation scales to be distinct from one another (Hardy et al. 2007; Padilla-Walker et al. in press). Participants were asked to respond to 28 items assessing internalization of the prosocial moral values of fairness, honesty, and kindness. Fourteen items $(\alpha=.94)$ assessed external regulation (e.g., "I am honest because my friends or parents would be disappointed if I wasn't honest") and 14 items $(\alpha=.89)$ assessed internal regulation (e.g., "I treat others fairly even if I don't like them because it is important to treat others fairly").

\section{Prosocial Tendencies}

Prosocial tendencies were assessed using the Prosocial Tendencies Measure (PTM; Carlo and Randall 2002). Factor analysis on this scale has revealed a distinct factor structure (Carlo et al. 2003; Carlo and Randall 2002); thus, this 25-item measure is composed of six subscales of context-specific prosocial tendencies: public (four items, $\alpha=.87$, sample item, "I can help others best when people are watching me"), compliant (two items, $\alpha=.69$, sample item, "When people ask me to help them, I don't hesitate"), emotional (five items, $\alpha=.85$, sample item, "I tend to help others particularly when they are emotionally distressed"), dire (three items, $\alpha=.79$, sample item, "I tend to help people who are in real crisis or need"), anonymous (five items, $\alpha=.84$, sample item, "I tend to help others in need when they do not know who helped them"), and altruistic ( ix items, $\alpha=.76$, sample item, "I often help even if I don't think I will get anything out of helping"). For each subscale, participants responded on a scale ranging from 1 (does not describe me at all) to 5 (describes me greatly).

\section{Results}

Descriptive Statistics and Correlations among Variables of Interest

Table 1 contains descriptive statistics and correlations among the study variables. It should be noted that all childreported relationship quality scales were correlated positively with internal regulation of prosocial values, but were not correlated with prosocial tendencies. Alternatively, internal regulation was correlated negatively with public prosocial tendencies and correlated positively with all other prosocial tendencies. Based on the significant bivariate correlations between variables, path analysis via structure equation modeling was used to gain clearer understanding of the multivariate relation between these variables and to examine the hypothesized model.

\section{Gender Differences}

A number of univariate analyses of variance (ANOVAs) were conducted to determine whether the outcome variables differed as a function of gender of the emerging adult. Results revealed that four of the eight outcome variables differed significantly by gender of the child. Namely, young men $(M=1.99, S D=.95)$ reported higher levels of public prosocial tendencies than did young women $(M=1.67, S D=.68), F(1,226)=9.03, p<.01$; 
Table 1 Correlations among relationship qualities, regulation, and prosocial tendencies

\begin{tabular}{|c|c|c|c|c|c|c|c|c|c|c|c|c|c|c|c|c|}
\hline & 1 & 2 & 3 & 4 & 5 & 6 & 7 & 8 & 9 & 10 & 11 & 12 & 13 & 14 & 15 & 16 \\
\hline \multicolumn{17}{|c|}{ Child-reported relationship qualities } \\
\hline 1. Support & - & & & & & & & & & & & & & & & \\
\hline 2. Companionship & $.59^{* * *}$ & - & & & & & & & & & & & & & & \\
\hline 3. Intimacy & $.79 * * *$ & $.61 * * *$ & - & & & & & & & & & & & & & \\
\hline 4. Aid & $.74 * * *$ & $.59^{* * *}$ & $.62^{* * *}$ & - & & & & & & & & & & & & \\
\hline \multicolumn{17}{|c|}{ Mother-reported relationship qualities } \\
\hline 5. Support & $.32^{* * *}$ & $.30^{* * *}$ & $.36^{* * *}$ & $.24 * *$ & - & & & & & & & & & & & \\
\hline 6. Companionship & $.17 *$ & $.23 * *$ & $.20^{* *}$ & .11 & $.66^{* * *}$ & - & & & & & & & & & & \\
\hline 7. Intimacy & $.27 * * *$ & $.27 * * *$ & $.32 * * *$ & $.19^{*}$ & $.83^{* * *}$ & $.68^{* * *}$ & - & & & & & & & & & \\
\hline 8. Aid & $.20 * *$ & $.17 *$ & $.25^{* *}$ & .12 & $.77 * * *$ & $.64 * * *$ & $.73 * * *$ & - & & & & & & & & \\
\hline \multicolumn{17}{|l|}{ Regulation } \\
\hline 9. External & $.13^{*}$ & .11 & .10 & $.19 * *$ & -.04 & -.05 & -.07 & -.05 & - & & & & & & & \\
\hline 10. Internal & $.22 * *$ & $.22 * *$ & $.25 * * *$ & $.25^{* * *}$ & .06 & .06 & .10 & -.02 & $.38^{* * *}$ & - & & & & & & \\
\hline \multicolumn{17}{|c|}{ Prosocial tendencies } \\
\hline 11. Public & .02 & .05 & .05 & -.03 & .13 & .10 & .06 & .11 & $.35^{* * *}$ & $-.13^{*}$ & - & & & & & \\
\hline 12. Compliant & $.13 *$ & .12 & .10 & .12 & -.04 & .04 & .02 & -.03 & .04 & $.43 * * *$ & $-.16^{*}$ & - & & & & \\
\hline 13. Emotional & .06 & .03 & .06 & .08 & -.09 & -.07 & -.06 & -.12 & .10 & $.30^{* * *}$ & .03 & $.52^{* * *}$ & - & & & \\
\hline 14. Dire & .01 & -.04 & .05 & .06 & -.02 & .00 & .00 & -.09 & .10 & $.22 * *$ & .07 & $.46^{* * * *}$ & $.65^{* * *}$ & - & & \\
\hline 15. Anonymous & -.04 & .01 & .05 & -.04 & .05 & .06 & .12 & .13 & -.01 & $.28 * * *$ & .08 & $.29 * * *$ & $.21^{* *}$ & $.35 * * *$ & - & \\
\hline 16. Altruistic & .04 & .01 & .01 & .11 & -.14 & -.05 & -.04 & $-.18^{*}$ & $-.22 * *$ & $.34 * * *$ & $-.62 * * *$ & $.28^{* * *}$ & .02 & -.08 & -.04 & - \\
\hline$M$ & 3.83 & 2.86 & 3.14 & 4.00 & 2.79 & 2.70 & 2.63 & 2.71 & 2.85 & 3.47 & 1.81 & 3.77 & 3.64 & 3.56 & 2.66 & 4.04 \\
\hline$S D$ & 1.06 & 0.95 & 1.11 & 0.90 & 1.04 & 0.84 & 1.04 & 0.91 & 0.65 & 0.45 & 0.82 & 0.91 & 0.83 & 0.86 & 0.92 & 0.68 \\
\hline
\end{tabular}

$* p<.05 ; * * p<.01 ; * * * p<.001$

young men $(M=3.70, S D=.81)$ reported higher levels of dire prosocial tendencies than did young women $(M=3.46, S D=.89), F(1,226)=4.45, p<.05$; young women $(M=4.13, S D=.61)$ reported higher levels of altruistic prosocial tendencies than did young men $(M=3.91, S D=.75), F(1,225)=6.00, p<.05 ;$ and young women $(M=3.59, S D=.38)$ reported higher levels of internal regulation of values than did young men $(M=3.32, S D=.48), F(1,226)=22.05, p<.001$. Due to these univariate gender differences, both measurement and structural invariance for men and women were examined within structural equation models.

\section{Measurement Model}

To confirm that the observed variables loaded on the latent factors of interest, a measurement model was estimated including latent constructs for child-reported relationship quality and mother-reported relationship quality (as indexed by child and mother-reported support, companionship, intimacy, and aid), using Mplus software (Muthén and Muthén 2006). Estimation of the measurement model yielded an acceptable fit, $\chi^{2}(12)=25.36, p<.05$, $\mathrm{CFI}=.99$, RMSEA $=.07, \mathrm{SRMR}=.03$, and all factor loadings were statistically significant at .58 or above (see Fig. 1). Correlations between the latent constructs showed that child- and mother-reported relationship quality were correlated moderately with one another $(r=.36, p<.05)$. A multiple group analysis where measurement invariance was tested across gender revealed that factor loadings were not different for men and women.

\section{Structural Model}

Next, a structural model was estimated modeling child- and mother-reported relationship quality as predictors of emerging adults' external and internal regulation of prosocial values. In turn, both external and internal regulation were used as predictors of emerging adults' prosocial tendencies (see Fig. 2). To determine whether the model functioned differently for men and women, the default model (wherein factor loadings were constrained to be equal across groups) was compared to a model where all structural paths were constrained to be equal across groups. A nonsignificant chi-square difference between the two models, $\chi^{2}(16)=18.70$, ns., suggests that the structural paths were not different, or that the model did not function differently for men and women. Although invariance tests suggested that gender was not a factor in the model, univariate tests suggested that gender was related to a number of the variables of interest. Thus, in the final model gender was included as a control variable.

Results of the final model, $\chi^{2}(85)=129.93, p<.001$; $\mathrm{CFI}=.97, \mathrm{RMSEA}=.05, \mathrm{SRMR}=.05$, revealed that 


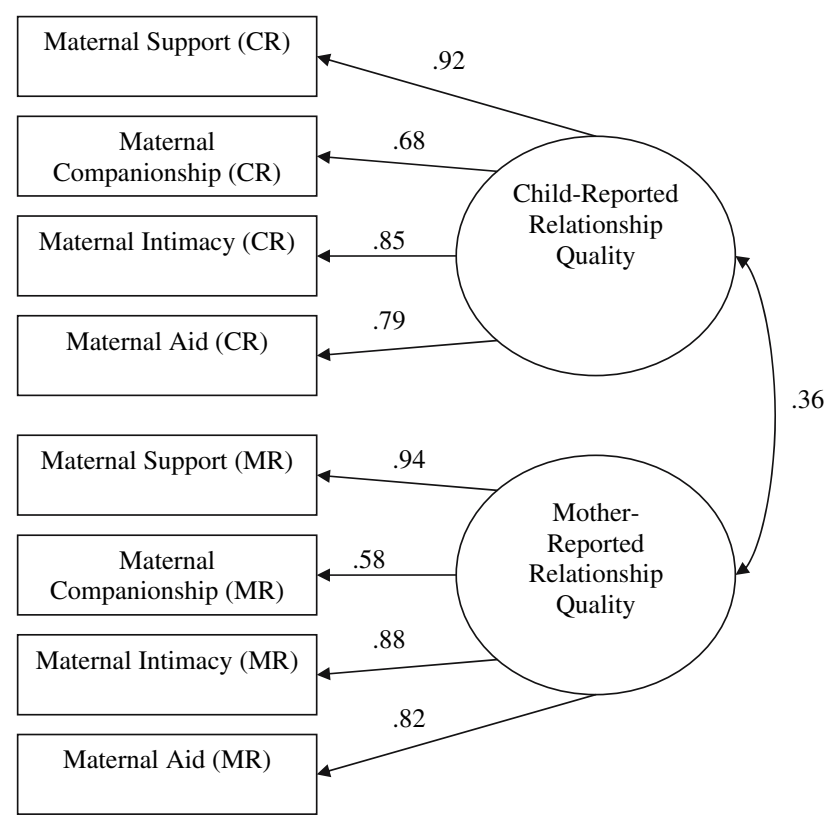

Fig. 1 Measurement model of child- and mother-reported relationship quality. Note. All weights are standardized. $\chi^{2}(28)=25.36$, $p<.001 ; \mathrm{CFI}=.99$, RMSEA $=.07$, SRMR $=.03$. CR indicates child-report and MR indicates mother-report

child-reported relationship quality significantly predicted both external and internal regulation of values, and that mother-reported relationship quality was unrelated to either regulation variables. In addition, external regulation was related positively to public prosocial tendencies, and related negatively to compliant, anonymous, and altruistic prosocial tendencies. Internal regulation was related negatively to public prosocial tendencies and related positively to compliant, emotional, dire, anonymous, and altruistic prosocial tendencies. There were no direct relations between relationship quality (child- or mother-reported) and prosocial tendencies, with or without regulation variables in the model. However, child-reported relationship quality was related indirectly to public prosocial tendencies $(\beta=.08, p<.05)$ via external regulation, and was related indirectly to all six prosocial tendencies (public, $\beta=-.06$, $p<.01$; compliant, $\beta=.13, p<.01$; emotional, $\beta=.08$, $p<.01$; dire, $\beta=.07, p<.01$; anonymous, $\beta=.09$, $p<.01$; and altruistic, $\beta=.12, p<.01$ ) via internal regulation. All possible residuals for dependent variables were correlated (correlations ranged from .06 to .33), but were not represented in the figure to simplify presentation. Gender was related positively to internal regulation ( $\beta=.26, p<.05$; women had the higher-coded value) and negatively to public $(\beta=-.19, p<.05)$, dire $(\beta=-.22$, $p<.05)$, and anonymous $(\beta=-.14, p<.05)$ prosocial tendencies. Gender also was related positively to both child- $(\beta=.22, p<.05)$, and mother- $(\beta=.17, p<.05)$ reported relationship quality variables. Together, the predictors accounted for $26 \%$ of explained variance in public prosocial tendencies, $22 \%$ of the variance in compliant prosocial tendencies, $10 \%$ of the variance in emotional prosocial tendencies, $10 \%$ of the variance in dire prosocial tendencies, $13 \%$ of the variance in anonymous prosocial tendencies, and $30 \%$ of the variance in altruistic prosocial tendencies.

\section{Discussion}

We investigated how mother-child relationship quality was related to prosocial tendencies via emerging adults'

Fig. 2 Structural model of relationship quality and regulation of prosocial values predicting emerging adults' prosocial tendencies. Note. All weights are standardized. $\chi^{2}(85)=129.93, p<.001$ $\mathrm{CFI}=.97, \mathrm{RMSEA}=.05$, SRMR $=.05$. Values in bold are statistically significant at $p<.01$. Values in bold and italics are statistically significant at $p<.05$. Variables represented by circles are latent variables

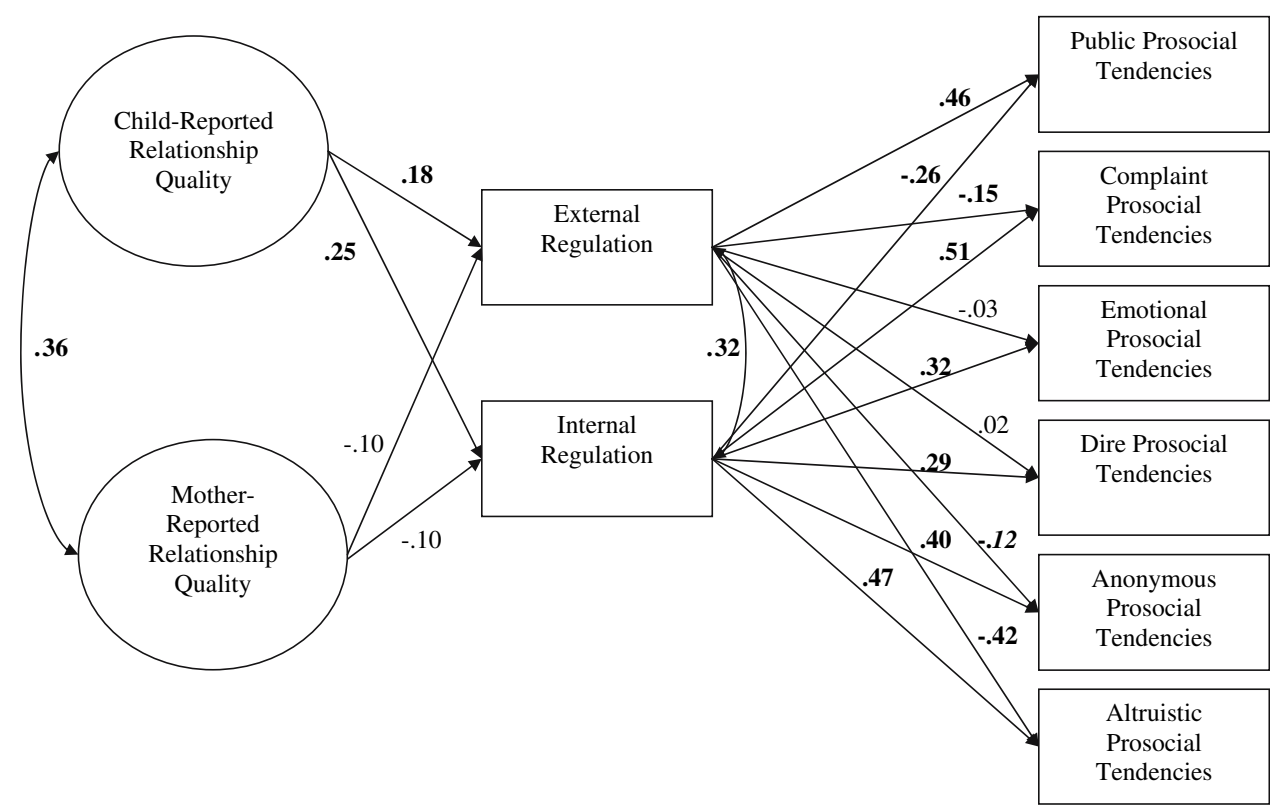


regulation of prosocial values. In support of our hypotheses, mother-child relationship quality (as perceived by the emerging-adult child) was related to emerging adults' regulation of prosocial values, which was, in turn, related to emerging adults' prosocial tendencies. In addition, findings revealed that child-reported relationship quality was related indirectly to all six prosocial tendencies by way of internal regulation, suggesting that although parenting may not be related directly to positive outcomes during emerging adulthood, this by no means suggests that parents no longer matter during the transition to adulthood.

\section{Parenting During Emerging Adulthood}

The study's results document the indirect relation between mother-child relationship quality and emerging adults' prosocial tendencies via regulation of positive values. Thus, parenting continues to be important in explaining emerging adults' behaviors, although the process by which mothers have the potential to shape their children's behavior may be more subtle, given that most have less direct contact with their children during this time period. These results are consistent with the existing literature on parenting adolescents (Steinberg and Silk 2002; Brown et al. 1993), and extend existing literature (e.g., Mussen and Eisenberg 2001) on how parenting is related to children's prosocial tendencies further in the lifespan, when those children are emerging adults.

\section{Socialization Processes}

The findings of the current study add to existing literature showing that the parent-child relationship serves as a context for socialization (Lawford et al. 2005). The process by which emerging adults come to display prosocial behavior starts when they are young, and parents have a potentially large role in the shaping of this behavior (Eisenberg and Fabes 1998). Over the course of development, children expand their involvement in social contexts, while simultaneously beginning to forge an independent sense of self from adolescence onward. During emerging adulthood, they are a part of multiple social contexts (e.g., parents' home, school, work, peers), all of which have the potential to influence their behavior.

The process by which primary socialization agents continue to contribute to emerging adults' behavior is admittedly complex. As predicted in the current study, emerging adults' regulation of prosocial values appears to be an important ingredient in accounting for their level and type of prosocial tendencies, which supports Darling and Steinberg's (1993) theoretical framework that the emotional climate between parents and their children can shape how children interpret parental behaviors. Given the unique goal of supporting emerging adults as they achieve increasing levels of autonomy, parents must adapt their parenting behaviors from those relied upon in adolescence. Future scholars should consider how other aspects of parenting (e.g., parental knowledge, parenting styles) contribute to emerging adults' positive outcomes. Given the numerous socialization contexts of which emerging adults are a part, future work should address not only how parents, but also how peers might contribute to emerging adults' display of prosocial behavior. It is plausible, for instance, that while parents indirectly influence their emerging adults, peers directly influence them given their more frequent level of interaction and noted importance to emerging adults (Carbery and Buhrmester 1998). It will be important for scholars to study numerous types of peer relationships to determine which ones may be most influential of prosocial behavior and under which situation (e.g., friends appear to be more influential if an emerging adult is without a romantic partner; Barry et al. 2007). It is important to note that the current study's findings are based upon a single point in time and, therefore, can be suggestive of directions for future work to test causal relations, namely longitudinal-sequential designs as well as quasiexperimental designs.

\section{Types of Prosocial Tendencies}

Mother-child relationship quality was related to different prosocial tendencies by way of the extent to which emerging adults regulated prosocial values. Public prosocial tendencies (e.g., prosocial tendencies motivated by social approval) were likely to occur when emerging adults reported high levels of external regulation of values, whereas compliant (i.e., helping when asked), emotional (i.e., helping in emotionally-charged situations), dire (i.e., helping in a crisis), anonymous (i.e., helping without others' knowledge), and altruistic prosocial tendencies (i.e., the least self-focused type of helping) were likely to occur when emerging adults reported high levels of internal regulation of prosocial values. In other words, emerging adults who had higher levels of internally-regulated prosocial values were more likely to engage in prosocial tendencies that de-emphasized themselves, and were less likely to engage in prosocial tendencies for the approval of others. According to Padilla-Walker et al. (in press), internal regulation of prosocial values has been associated with identity achievement, whereas external regulation has been associated with identity diffusion. Thus, the current study's findings, taken in conjunction with other work, suggest that emerging adults are making the necessary 
psychological adjustments (i.e., internal regulation of values) that support individuation from parents by striving toward identity achievement and, in turn, their successful transition to adulthood. Following individuals longitudinally throughout emerging adulthood is necessary to examine the regulation of prosocial values more closely to determine if it, in fact, is an important mechanism in achieving adulthood criteria, and in so doing, conceptualizing oneself as an adult.

\section{Relationship Quality as a Function of Reporter}

Results were significant only for emerging adults' perspective of the mother-child relationship, and not the mothers' perspective. Certainly, mothers and their children are likely to perceive their relationship differently (as supported by posthoc correlational analyses that found only weak correlations between child- and mother-reported relationship quality scales), and this disparity might be more salient during emerging adulthood when geographical distance tends to be more extreme. Moreover, what the emerging adults perceive of their relationships with their mothers is likely to be more strongly related to their own behavior than what their mothers perceive of this relationship. However it is important to acknowledge that this finding also can be explained by common method variance given the use of self-report data.

\section{Limitations and Future Directions}

The current study was not without limitations. First, the sample was comprised of emerging adults who attended a college or university within the United States and may not be generalizable to emerging adults who are not enrolled in higher education. Critics of Arnett's (2004) theory of emerging adulthood contend that the theory is culturally defined and only applicable to a select stratum of Western, middle-class culture, and not the range of social, economic, cultural, ethnic, and religious subgroups (Collins and Madsen 2006). However, Nelson (2007) suggested that the period of emerging adulthood is optimal for healthy development even if not all individuals have the opportunity for prolonged exploration. Further, there has been little research examining ethnic differences in positive outcomes during emerging adulthood (c.f., Blaine and Crocker 1995; Padilla-Walker et al. in press; Walker and Bishop 2005), but research has found that frequency of risk behaviors (e.g., Laird and Shelton 2006; Mounts 2004) and parenting (Lamborn et al. 1991) differ widely by ethnicity and culture. Given the dearth of studies on non-college, nonWestern samples of young people, future research would benefit from focusing on obtaining more diverse samples in order to understand the nature of parent-child relationships on young people's developmental outcomes more fully.

Additionally, the study's findings were all based upon self-report measures (albeit using two informants for parent-child relationship quality). In the future, scholars should obtain other informants' evaluations of emerging adults' prosocial tendencies, thereby increasing the study's internal validity. Further, the use of the Internet to collect such measures may be seen as a limitation. Online surveys are sometimes viewed as problematic given that not all potential participants have access to the Internet. However, the use of Internet surveys among college populations may be just as effective, if not more effective, than using paper and pencil measures, given that nearly $100 \%$ of college students have access to the Internet (Stanton 1998).

Gender was controlled for in the current study. Scholars have shown that the parent-child relationship varies by gender of both the child and parent (see Fagot 1995; Lamb et al. 1999; Nelson et al. in press). Thus, it is a limitation that the relationship quality with fathers or both mothers and fathers was not examined in the study. Women are more likely to engage in prosocial behavior (Eisenberg and Fabes 1998) and traditionally conceptualize themselves based upon their relationships more than their achievements (i.e., interdependent self-construals, Cross and Madson 1997). Thus, results that focus exclusively on mother-child relationship quality likely yield a stronger connection between parenting and some types (e.g., less self-focused) of prosocial tendencies than if fathers were studied. Scholars need to obtain a sufficient sample size of both mothers and fathers and emerging-adult sons and daughters to examine the range of possible effects of parenting on the many types of emerging adults' prosocial tendencies.

\section{Conclusion}

Mother-child relationship quality was related to emerging adults' regulation of prosocial values, which in turn was related to prosocial tendencies. Despite the limitations of the study, the findings contribute to our understanding of young people as they transition to adulthood by documenting the continued importance of parents (namely, mothers) in the lives of their children. The findings offer preliminary support for a socialization process (via regulation of values) by which parenting still matters in children's lives, despite fewer opportunities for direct supervision and contact. In addition, findings highlight emerging adults' regulation of prosocial values as an important predictor of prosocial tendencies, and document the importance of research that more carefully explores 
correlates of emerging adults' individual values and beliefs.

Acknowledgements The authors wish to thank Kevin Hughes for his early work on this manuscript in reviewing relevant literature and data analyses. The authors are also grateful for the statistical help of Joe Olsen and Jeremy Yorgason. We also express appreciation to the instructors and participants at all Project READY data collection sites for their assistance. The authors also are grateful to the junior faculty sabbatical grant given to the first author by Loyola College in Maryland and the grant support of the Family Studies Center at Brigham Young University.

\section{References}

Arnett, J. J. (2000). Emerging adulthood: A theory of development from the late teens through the twenties. American Psychologist, $55,469-480$.

Arnett, J. J. (2003). Conceptions of the transition to adulthood among emerging adults in American ethnic groups. New Directions in Child and Adolescent Development, 100, 63-75.

Arnett, J. J. (2004). Emerging adulthood: The winding road from the late teens through the twenties. New York: Oxford University Press.

Bardi, A., \& Schwartz, S. H. (2003). Values and behavior: Strength and structure of relations. Personality and Social Psychology Bulletin, 29, 1207-1220.

Barry, C. M., Madsen, S. D., Nelson, L. J., Carroll, J. S., \& Badger, S. (2007). Friendship and romantic relationship qualities in emerging adulthood: Differential association with progress on identity development and societal tasks. Manuscript submitted for publication.

Barry, C. M., \& Wentzel, K. R. (2006). Friend influence on prosocial behavior: The role of motivational factors and friendship characteristics. Developmental Psychology, 42, 153-163.

Bartle-Haring, S., Brucker, P., \& Hock, E. (2002). The impact of parental separation anxiety on identity development in late adolescence and early adulthood. Journal of Adolescent Research, 17, 439-450.

Blaine, B., \& Crocker, J. (1995). Religiousness, race, and psychological well-being: Exploring social psychological mediators. Personality and Social Psychology Bulletin, 21, 1031-1041.

Blieszner, R., \& Wingfield, N. P. (2000). Parent-child relationship: Adulthood. In A. E. Kazdin (Ed.), Encyclopedia of psychology (Vol. 6, pp. 55-61). Washington: American Psychological Association.

Bornstein, M. H. (2006). Parenting science and practice. In K. A. Renninger, W. Damon, \& R. M. Lerner (Eds.), Handbook of child psychology, vol. 4, child psychology in practice (6th ed., pp. 893-949). Hoboken: Wiley.

Bowlby, J. (1969). Attachment and loss: Vol. 1. Attachment. New York: Basic Books.

Brown, B. B., Mounts, N., Lamborn, S. D., \& Steinberg, L. (1993). Parenting practices and peer group affiliation in adolescence. Child Development, 64, 467-482.

Buri, J. R. (1987). Familial correlates of self-esteem in young American adults. Journal of Social Psychology, 127, 583-588.

Carbery, J. D. (1993). The changing significance of friendship across three young adult phases. Unpublished doctoral dissertation, The University of Texas at Dallas.

Carbery, J., \& Buhrmester, D. (1998). Friendship and need fulfillment during three phases of young adulthood. Journal of Social and Personal Relationships, 15, 393-409.
Carlo, G., Hausmann, A., Christiansen, S., \& Randall, B. A. (2003). Sociocognitive and behavioral correlates of a measure of prosocial tendencies for adolescents. Journal of Early Adolescence, 23, 107-134.

Carlo, G., \& Randall, B. A. (2001). Are all prosocial behaviors equal? A socioecological developmental conception of prosocial behavior. In F. Columbus (Ed.), Advances in psychology research, volume II (pp. 151-170). New York: Nova Science.

Carlo, G., \& Randall, B. A. (2002). The development of a measure of prosocial behaviors for late adolescents. Journal of Youth and Adolescence, 31, 31-44.

Carroll, J. S., Willoughby, B., Badger, S., Nelson, L. J., Barry, C. M., \& Madsen, S. D. (2007). So close, yet so far away: The impact of varying marital horizons on emerging adulthood. Journal of Adolescent Research, 22, 219-247.

Collins, W. A., \& Madsen, S. D. (2006). Personal relationships in adolescence, early adulthood. In D. Perlman \& A. Vangelisti (Eds.), The Cambridge handbook of personal relationships (pp. 191-209). New York: Cambridge University Press.

Cross, S. E., \& Madson, L. (1997). Models of the self: Self-construals and gender. Psychological Bulletin, 122, 5-37.

Dalton, W. T., Frick-Horbury, D., \& Kitzmann, K. M. (2006). Young adults' retrospective reports of parenting by mothers and fathers: Associations with current relationship quality. The Journal of General Psychology, 133, 5-18.

Darling, N., \& Steinberg, L. (1993). Parenting style as a context: An integrative model. Psychological Bulletin, 113, 487-496.

Eisenberg, N. (1986). Altruistic emotion, cognition and behavior. Hillsdale: Erlbaum.

Eisenberg, N., \& Fabes, R. A. (1998). Prosocial development. In W. Damon (Series Ed.) \& N. Eisenberg (Vol. Ed.), Handbook of child psychology, vol. 3: Social, emotional, and personality development (5th ed., pp. 701-778). New York: Wiley.

Eisenberg, N., Guthrie, I. K., Cumberland, A., Murphy, B. C., Shepard, S. A., Zhou, Q., \& Carlo, G. (2002). Prosocial development in early adulthood: A longitudinal study. Journal of Personality and Social Psychology, 82, 993-1006.

Eisenberg, N., \& Murphy, B. (1995). Parenting and children's moral development. In M. H. Bornstein (Ed.), Handbook of parenting, vol. 4: Applied and practical parenting (pp. 227-257). Hillsdale: Lawrence Erlbaum.

Eisenberg, N., Zhou, Q., \& Koller, S. (2001). Brazilian adolescents' prosocial moral judgment and behavior: Relations to sympathy, perspective taking, gender role orientation, and demographic characteristics. Child Development, 72, 518-534.

Elliott, R., \& Vasta, R. (1970). The modeling of sharing: Effects associated with vicarious reinforcement, symbolization, age, and generalization. Journal of Experimental Child Psychology, 10, $8-15$.

Fabes, R. A., Carlo, G., Kupanoff, K., \& Laible, D. (1999). Early adolescence and prosocial/moral behavior $\mathrm{I}$ : The role of individual processes. Journal of Early Adolescence, 19, 5-16.

Fagot, B. I. (1995). Parenting boys and girls. In M. H. Bornstein (Ed.), Handbook of parenting: Vol. 1. Children and parenting (pp. 163-183). Mahwah: Erlbaum.

Grolnick, W. S., Deci, E. L., \& Ryan, R. M. (1997). Internalization within the family: The self-determination theory perspective. In J. E. Grusec \& L. Kuczynski (Eds.), Parenting and children's internalization of values: A handbook of contemporary theory (pp. 135-161). Hoboken: Wiley.

Grusec, J. E. (2006). The development of moral behavior and conscience from a socialization perspective. In M. Killen \& J. Smetana (Eds.), Handbook of moral development (pp. 243-265). Mahwah: Lawrence Erlbaum.

Grusec, J. E., \& Goodnow, J. J. (1994). Impact of parental discipline methods on the child's internalization of values: A 
reconceptualization of current points of view. Developmental Psychology, 30, 4-19.

Hardy, S. A., Padilla-Walker, L. M., \& Carlo, G. (2007). Parenting styles and adolescents' internalization of moral values. Manuscript submitted for publication.

Holmbeck, G. N., Paikoff, R. L., \& Brooks-Gunn, J. (1995). Parenting adolescents. In M. H. Bornstein (Ed.), Handbook of parenting, vol. 1: Children and parenting (pp. 91-118). Hillsdale: Lawrence Erlbaum.

Jensen, L. A., Arnett, J. J., Feldman, S. S., \& Cauffman, E. (2004). The right to do wrong: Lying to parents among adolescents and emerging adults. Journal of Youth \& Adolescence, 33, 101-112.

Kochanska, G. (1995). Children's temperament, mother's discipline, and security of attachment: Multiple pathways to emerging internalization. Child Development, 66, 597-615.

Knafo, A., \& Plomin, R. (2006). Parental discipline and affection and children's prosocial behavior: Genetic and environmental links. Journal of Personality and Social Psychology, 90, 147-164.

Laible, D. J., Carlo, G., \& Roesch, S. C. (2004). Pathways to selfesteem in late adolescence: The role of parent and peer attachment, empathy, and social behaviours. Journal of Adolescence, 27, 703-716.

Laird, T. G., \& Shelton, A. J. (2006). Letter to the editor: Comparison of alcohol use in an ethnically diverse sample of women attending two urban universities. Journal of Alcohol and Drug Education, 50, 14-24.

Lamb, M. E., Hwang, C. P., Ketterlinus, R. D., \& Fracasso, M. P. (1999). Parent-child relationships: Development in the context of the family. In M. H. Bornstein \& M. E. Lamb (Eds.), Developmental psychology: An advanced textbook (pp. 411450). Mahwah: Erlbaum.

Lamborn, S. D., Mounts, N. S., Steinberg, L., \& Dornbusch, S. M. (1991). Patterns of competence and adjustment among adolescents from authoritative, authoritarian, indulgent, and neglectful families. Child Development, 62, 1049-1065.

Lawford, H., Pratt, M. W., Hunsberger, B., \& Pancer, S. M. (2005). Adolescent generativity: A longitudinal study of two possible contexts for learning concern for future generations. Journal of Research on Adolescence, 15, 261-273.

Logan, J., \& Spitze, G. (1996). Family ties: Enduring relations between parents and their grown children. Philadelphia: Temple University Press.

Mayseless, O., \& Scharf, M. (2003). What does it mean to be an adult? The Israeli experience. In J. J. Arnett \& N. L. Galambos (Eds.), New directions in child development: Exploring cultural conceptions of the transition to adulthood, No. 100 (pp. 5-20). San Francisco: Jossey-Bass.

Mounts, N. S. (2004). Contributions of parenting and campus climate to freshmen adjustment in a multiethnic sample. Journal of Adolescent Research, 19, 468-491.

Mussen, P., \& Eisenberg, N. (2001). Prosocial development in context. In A. C. Bohart \& D. J. Stipek (Eds.), Constructive and destructive behavior: Implications for family, school and society (pp. 103126). Washington: American Psychological Association.

Muthén, L. K., \& Muthén, B. O. (2006). Mplus user guide (4th ed.). Los Angeles: Muthén \& Muthén.

Nelson, L. J. (2007). Perceived status on adulthood, adult roles, and culture: An examination of emerging adulthood in Romania. Manuscript submitted for publication.

Nelson, L. J., \& Barry, C. M. (2005). Distinguishing features of emerging adulthood: The role of self-classification as an adult. Journal of Adolescent Research, 20, 242-262.

Nelson, L. J., Padilla-Walker, L. J., Carroll, J. S., Madsen, S. D., Barry, C. M., \& Badger, S. (in press). "If you want me to treat you like an adult, start acting like one!" Comparing the criteria that emerging adults and their parents have for adulthood. Journal of Family Psychology.

O’Connor, T. G., Allen, J. P., Bell, K. L., \& Hauser, S. T. (1996). Adolescent-parent relationships and leaving home in young adulthood. New Directions for Child Development, 71, $39-52$.

Padilla-Walker, L. M., Barry, C. M., Carroll, J. S., Madsen, S. D., \& Nelson, L. J. (in press). Looking on the bright side: The role of identity status and gender on positive outcomes during emerging adulthood. Journal of Adolescence.

Padilla-Walker, L. M., \& Carlo, G. (2007). Personal values as a mediator between parent and peer expectations and adolescent behaviors. Journal of Family Psychology, 21, 538-541.

Padilla-Walker, L. M., Nelson, L. J., Madsen, S. D., \& Barry, C. M. (2007). The role of perceived parental knowledge on emerging adults' risk behaviors. Manuscript submitted for publication.

Ryan, R. M., \& Connell, J. P. (1989). Perceived locus of causality and internalization: Examining reasons for acting in two domains. Journal of Personality and Social Psychology, 57, 749-761.

Schulenberg, J. E., \& Zarrett, N. R. (2006). Mental health during emerging adulthood: Continuity and discontinuity in courses, causes, function. In J. J. Arnett \& J. L. Tanner (Eds.), Emerging adults in America: Coming of age in the 21st century (pp. 135172). Washington: American Psychological Association.

Stanton, J. M. (1998). An empirical assessment of data collection using the Internet. Personnel Psychology, 51, 709-725.

Steinberg, L., \& Silk, J. S. (2002). Parenting adolescents. In M. H. Bornstein (Ed.), Handbook of parenting: Vol. 1: Children and parenting (2nd ed., pp. 103-133). Mahwah: Erlbaum.

Walker, R. L., \& Bishop, S. (2005). Examining a model of the relation between religiosity and suicidal ideation in a sample of African American and white college students. Suicide and LifeThreatening Behavior, 35, 630-639.

Wentzel, K. R., Barry, C. M., \& Caldwell, K. A. (2004). Friendship in middle school: Influences on motivation and school adjustment. Journal of Educational Psychology, 96, 195-203.

\section{Author Biographies}

Carolyn McNamara Barry is an Assistant Professor of Psychology at Loyola College in Maryland. She received her Ph.D. in 2001 from the University of Maryland, College Park. Her major research interests are in social and self development during adolescence and emerging adulthood.

Laura M. Padilla-Walker is an Assistant Professor in the School of Family Life at Brigham Young University. She received her Ph.D. in 2005 from the University of Nebraska-Lincoln. Her major research interests center on the parent-adolescent relationship as it relates to adolescents' moral and prosocial behaviors and internalization of values.

Stephanie D. Madsen is an Associate Professor of Psychology at McDaniel College. She received her Ph.D. in 2001 from the Institute of Child Development, University of Minnesota. She is particularly interested in how relationships with significant others impact child and adolescent development.

Larry J. Nelson is an Associate Professor in the School of Family Life at Brigham Young University. He received his Ph.D. in 2000 from the University of Maryland, College Park. His major research interests are in social and self development during early childhood and emerging adulthood. 